\title{
Facework Strategies in EFL Classroom
}

\author{
Qian Huang \\ School of Foreign Languages, Zhejiang University of Finance \& Economics, Hangzhou, China
}

\begin{abstract}
Facework strategy, which takes learners' face-needs into account, is a dispensable part in teaching strategies. Based on researches done on facework, this study examines college English teachers' application of facework strategies within EFL classroom, mainly by means of qualitative and quantitative methods. It presents a picture of how teachers use facework strategies in the EFL classroom, especially how teachers use different facework strategies to satisfy learners' face-needs in class. The analysis of the study proves that no matter what types of facework strategies are applied, the purpose is to create a pleasant and harmonious context for the learners, to initiate their self-esteem and enthusiasm in their study, and achieve effective teaching.
\end{abstract}

Index Terms - face, facework strategies, EFL classroom, face-needs

\section{INTRODUCTION}

Face is defined as "the positive social value a person effectively claims for himself by the line others assume he has taken during a particular contact" (Goffman, 1967, p.9), which, however, "is only on loan to him from society" and "it will be withdrawn unless he conducts himself in a way that is worthy of it" (Goffman, 1972, p.322). In order to maintain face, a person takes into account his or her position in society and normally refrains from carrying out actions or taking part in activities that would be awkward to other interactants.

Facework is broadly defined as the actions taken to deal with the face-wants of one or another. It involves the enactment of verbal and nonverbal moves, self-presentation acts, impression management interaction and face strategies which can be used to diffuse, manage, enhance, or downgrade self or other's face. It concerns a set of communicative behaviors that people use to regulate their social dignity and to support or challenge the other's social dignity. (Ting-Toomey, 1994)

Facework strategies (FS), which have been the focus of a great many researches in recent years, are essential to language classroom teaching. Since Goffman (1967) proposed the notion of face and later Brown and Levinson (1978) developed it by putting forward the Face Theory, many researchers have explored it in various fields.

\section{IMPLEMENTATION OF THE STUDY}

Over the past few years, there have been numerous studies examining facework and conflict styles across cultures. However, researches focus only on a narrow range of face concern and face management. We feel that measures or survey of face concerns and facework patterns in EFL classroom should be included for our current study, especially for further research on language teaching. Therefore, we attempt to conduct it by questionnaires both for EFL teachers and learners.

The questionnaires were carried out in three universities in China (Central South University, Hunan City University and Changsha Social Work College). All participants completed the questionnaires in their native language. Altogether 50 teachers and 96 learners participate in the study and all participants remained anonymous in the study. The average age of the teacher participants is 38.4 , and the average age of learners is 21.7 . Among these participants, $73 \%$ are female and $27 \%$ are male.

\section{A. Teachers'Questionnaire}

Teachers' questionnaires were delivered to 50 participants, who all returned the questionnaires, that is, $100 \%$ response rate has been obtained.

The teachers' questionnaire is designed to reveal (1) their concern for learners' face, (2) their current application of FS (i.e. in what circumstances face is given or refused), (3) the effects of FS on EFL teaching, (4) their attitudes toward the FS applied in class.

Section 1 contains multiple choice items requiring participants to choose an item which indicates their answer to the question. Section 2 contains five-point scale items requiring teachers to evaluate their practice of FS in EFL classrooms. These scales help capture answers to the research questions quickly and in very little space.

Altogether, the questionnaire is made up of 15 items, six of which are multiple choices and nine of which are scaled items ranging from "strongly agree" to "strongly disagree" (i.e. strongly agree $=1$, agree $=2$, no opinion $=3$, disagree $=4$, strongly disagree $=5$ ).

Of all the respondents 9 are male accounting for $18 \%$ and 41 are female accounting for $82 \% .24$ at the percentage of 48 are under the age of 30; 17 at the percentage of 34 are between 31 and 40 years old; 6 at the percentage of 12 are 
between the age of 41-50; and 3 at the percentage of 6 are over the age of 50. As far as their professional titles are concerned, $50 \%$ of the teachers hold the professional title of assistants, the highest percentage in this category; $32 \%$ of them are lecturers; $18 \%$ of them are associated professors. As to their teaching history, $18 \%$ have been teaching for 5-10 years, $22 \%$ for $11-20$ years, $12 \%$ for over 20 years, and $48 \%$ for less than 5 years.

This questionnaire covers four main questions, which include teachers' face-concern for the learners, their practice of FS in EFL class, the effects of FS application and the goals for applying FS.

The data are submitted to several factor analyses in order to understand the facework strategies applied in an EFL classroom and confirm the necessity of the measures. We complete separate factor analyses for face concerns, facework strategies and effects of FS application. We use the following procedures for each of the factor analyses. First, all data are standardized within the Chinese culture. Second, the data for face concerns, practice of FS and effects of FS are submitted to principal components of factor analyses with scaled rotation because of the expected correlation among factors.

The first factor analysis is for teachers' face concerns. Two factors composed of 5 items accounting for $33.3 \%$ of the variance are discovered. The first factor consists of 2 items focusing on teachers' concern for the students' poise, pride, face, and credibility. In Item 2 when asked whether they are aware of learners' hope for face-saving during the teaching process, $66 \%$ of the teacher participants indicate that they frequently do that; $32 \%$ sometimes, and only $2 \%$ seldom. In Item $6,68 \%$ of the participants are frequently aware of learners' face-need, $14 \%$ sometimes, and only $4 \%$ seldom concern with about learners' face. The second factor consists of 3 items, accounting for $20 \%$ of the variance. The items focus on teachers' perceptions of learners' face-needs. In answering what is the main reason for learners' lacking of motivation in English class in Item 1, 50\% of the participants point out that it is their fear of making mistake and losing face; $34 \%$ think that it is because of their poor foundation in English learning. The results of Item 7 reveals that $50 \%$ of the teachers think that learners care much about their images and position in others' eyes, $6 \%$ have no opinion, but $36 \%$ of them don't think so. As to Item 15, the strong disagreement and disagreement for the statement that it is unnecessary for the teacher to consider the face issues in EFL classroom are respectively $50 \%$ and $38 \%$.

The second factor analysis is for teachers' FS in EFL classroom. Three factors accounting for $20 \%$ of the variance are discovered. The first factor consists of one item, accounting for $6.7 \%$ of the variance. The item focuses on the behavior that attempts to resolve a conflict through compromising or integrating viewpoints. In this item (Item 4), participants are asked what is the strategy they often apply in the time they have to threaten their students' face. $46 \%$ of them explain to their students, $50 \%$ try to minimize the face-threat and only $4 \%$ take no action. The second factor consisted of one item -- Item 5, accounting for $6.7 \%$ of the variance. It reveals that all the participants will encourage their students and give them support when they are in trouble with English study. The item of this factor focuses on trying to maintain composure during conflict and not getting angry. The third factor has one item -- Item 3, accounting for $6.7 \%$ of the variance. When asked what their attitudes toward students' mistake in class are, $12 \%$ choose to point out immediately, $58 \%$ usually point out individually after class, and 30\% indicate they will guide them to solve the problem with patience. The emphasis on this item is the desire to avoid an argument in public.

The third factor analysis is for effects of FS application. Two factors composed of 6 items accounting for $40 \%$ of the variance are discovered. The first factor consists of 2 items, accounting for $13.3 \%$ of the variance. The items focus on effects of FS on learners. The second factor consists of 4 items, accounting for $26.7 \%$ of the variance. The items focus predominately on the influence of FS on EFL teaching.

According to the areas in the questionnaire, specific results are found. The information in table I is intended to provide an all-round view of effects of FS on teaching and learning.

TABLE I:

EFFECTS OF FS ON TEACHING AND LEARNING

\begin{tabular}{|l|l|l|l|l|l|}
\hline Item & Strongly Agree & Agree & No opinion & Disagree & Strongly disagree \\
\hline 10 & $82 \%$ & $16 \%$ & $2 \%$ & & \\
\hline 11 & $40 \%$ & $38 \%$ & $14 \%$ & $6 \%$ & $2 \%$ \\
\hline 13 & $10 \%$ & $10 \%$ & $4 \%$ & $56 \%$ & $20 \%$ \\
\hline 14 & & $2 \%$ & $4 \%$ & $54 \%$ & $40 \%$ \\
\hline
\end{tabular}

Table I summarizes the degree to which teachers feel about the influence of FS in an EFL classroom. The point (98\%) of Item 10 is the highest in terms of agreement for positive effect of teacher's smile and encouragement in stimulating learners' motivation in English study. As for Item 11, the point (78\%) is also high in term of agreement on "learners' interest in learning can be motivated by realizing their face-needs." It shows satisfying learners' face-needs is a basic requirement for FS, such as understanding students' interests and high request for increasing face-saving and less demand for face-threatening.

It seems clear from the results that teachers have a high awareness of the fundamental roles of FS in stimulating interactive classroom activities and practicing effective teaching. The point (76\%) is high in terms of disagreement on the statement of Item 13 "the construction of harmonious relationship between the teacher and learners will not be affected by the consideration of learners' face-needs". Results of Item 14 also show that, the majority of teachers (94\%) are against the given statement which indicates that "maintenance of learners' face has no influence on achieving a successful teaching in EFL classrooms". These may suggest that the teachers might be influenced by the learners' 
variables and consider more about their needs and interests when applying FS.

The above results of the factor analysis demonstrate that face concerns, facework strategies and effects of FS application can be measured consistently. The items for face concerns measure the teachers' face-concern for their students. These are consistent with expectations of prior theoretical research (Ting-Toomey \& Kurogi, 1998). Each of these measures, furthermore, have good reliabilities. Thus, this instrument is useful for researchers and facilitators who are interested in measuring the application of facework. The items for facework strategies measure 3 distinct factors. This discovery is important because it demonstrates a wide variety of strategies that are used to manage face-needs during an EFL classroom conflict. The majority of the facework dimensions have good reliabilities.

Having reviewed the features of various facework strategies and their effects respectively, we may summarize that teachers often use FS when they are trying to accomplish the following goals such as minimizing their conflict with learners, increasing learners' interests in class, or enhancing their self-esteem. These are consistent with the data of Table I. Then Item 8, Item 9 and Item 12 attempt to investigate such goals that reversely help us to understand the reasoning behind teachers' actual practice. The results are showed in Table II.

TABLE II:

MEAN AGREEMENT WITH OPINION STATEMENTS ABOUT GOALS FOR APPLYING FACEWORK STRATEGIES

\begin{tabular}{|l|l|l|}
\hline Item & Goals for Applying FS & Mean \\
\hline 8 & $\begin{array}{l}\text { It is necessary for the teachers to perceive their students' mentality in order to enhance } \\
\text { teaching. }\end{array}$ & 4.2 \\
\hline 9 & $\begin{array}{l}\text { Effective classroom teaching strategies should satisfy students' face-needs as much as } \\
\text { possible. }\end{array}$ & 3.8 \\
\hline 12 & $\begin{array}{l}\text { The classroom teaching which integrates with "face" issues is much promising than that } \\
\text { which does not. }\end{array}$ & 3.3 \\
\hline
\end{tabular}

Table II shows virtually all teachers expect to spend some time leading the whole class in a non-conflict context, with each mean being above 3. The mean for applying FS to enhance teaching is 4.2 , which is the highest. The mean for adopting FS to satisfy learners' face-needs is 3.8. The mean for achieving a promising teaching is 3.3, ranking third in this table. The results show teachers seem to hold beliefs about employing FS for more communicative oriented purposes than traditional transmission purposes. The results are consistent with the results shown from Table I.

Table I-II show that these participants believe that teachers who employ FS to satisfy learners' face-needs and create more enjoyable and harmonious interactions in EFL classroom are more promising than those just give the lesson to accord with the teaching plan. So the demand for teachers to adopt more FS in the classroom becomes clearer.

\section{B. Learners'Questionnaire}

Learners' questionnaires were delivered to 96 participants, and 95 of them were returned, that is, almost $99 \%$ participants give their response in the study.

The learners' questionnaire is designed to investigate (1) their face-needs in class, (2) the current application of FS by their EFL teachers, (3) their reaction and feedback to gaining or losing face, (4) the effects on their learning.

Section 1 contains multiple choice items requiring participants to choose an item which exactly indicates their answer to the questions. Section 2 contains five-point scale items requiring learners to assess their experience of teacher's FS in EFL classroom.

Like the teachers' questionnaire, it is also made up of 15 items, six of which are multiple choices and nine of which are scaled items ranging from "strongly agree" to "strongly disagree".

Of the returned 95 copies 25 respondents are male, making up 26.3\%; 70 are female, making up $73.7 \%$. 25 copies of questionnaire were distributed among first-year learners and 24 copies were returned; 6 respondents are male amounting to $24 \%$ and 19 respondents are female amounting to $76 \% .42$ copies of questionnaire were distributed among second-year learners; of the respondents 12 are male amounting to $28.6 \%$ and 30 are female amounting to $71.4 \%$. 38 copies of questionnaire were handed out to third-year learners, and among them 7 respondents are male making up $18.4 \%$ and 37 respondents are female making up $81.6 \%$.

This questionnaire covers three main questions, including learners' face-needs, current issues of teachers' FS in EFL classroom, and the impacts of FS application.

The first factor analysis is for learners' face-needs. The factor is composed of 3 items (Item 1, Item 2, Item 6) accounting for $20 \%$ of the variance. The items focus predominately on the learners' concern for freedom, self-esteem, and confidence. In Item 1, 33.7\% participants indicate that they frequently hope that their teacher will give support when they meet some difficulty in English study, 47.4\% sometimes, $14.7 \%$ seldom and only $4 \%$ never. When asked what do they wish their teacher to do when they make mistakes in class, $1 \%$ of the participants hope that their teacher pays no attention, $11.6 \%$ hope that the teacher points out the mistake indirectly in class, $42.1 \%$ hope to be pointed out individually after class and $45.3 \%$ hope that the teacher guide them to solve the problem patiently. The result of Item 6 shows that $12.6 \%$ of learner participants do not care about whether their teacher satisfies their face-needs or not, $50.5 \%$ point out that they will be in low spirits if their face-needs are not met, 33.7\% will have a negative impression on their teacher and 3.2\% will express their disapproval in class when their teacher fails to maintain their face.

The second factor analysis is for teachers' facework strategies. 3 factors accounting for $26.7 \%$ of the variance are discovered. The first factor consists of one item, accounting for $6.7 \%$ of the variance. Item 4 reveals that when in 
conflict with learners' opinions, the teacher will employ various strategies. $44.2 \%$ participants indicate that their teacher will solve the problem together with them, $31.6 \%$ of the teacher will persuade them to accept his or her own opinion, $22.1 \%$ point out their teacher will avoid the topic in discussion, and only $2 \%$ indicate that their teacher will accept the learners' opinion. This item focuses on behaviors that attempt to resolve a conflict through compromising or integrating viewpoints. The second factor consists of one item -- Item 3, accounting for $6.7 \%$ of the variance. The item focuses on trying to maintain composure during conflict and not getting angry. 32.3\% indicate that their teacher often point out their mischievous behavior individually after class, $12 \%$ point out publicly, $2 \%$ criticize their students strongly and $52.7 \%$ correct it indirectly. The third factor consists of 2 items (Item 5 and Item 12), accounting for $13.3 \%$ of the variance. $47.4 \%$ participants indicate most of their teachers in their former English study took measures to save their face and only $3.2 \%$ point out few of their teachers take measures. As to the statement in Item $12,73.7 \%$ strongly agree that because many teachers still haven't changed the role of controller in classroom teaching, the students' potentiality in study cannot be exposed, $16.8 \%$ have their reservations, and only $9.4 \%$ disagree with it. These items have explored the current face management by teachers in EFL classrooms.

The third factor analysis is for the impacts of FS on learners. We can see the results from the table below:

TABLE III:

IMPACTS OF FS ON LEARNERS

\begin{tabular}{|l|l|l|l|l|l|}
\hline Item & $\begin{array}{l}\text { Strongly } \\
\text { Agreeing }\end{array}$ & Agreeing & No opinion & Disagreeing & $\begin{array}{l}\text { Strongly } \\
\text { disagreeing }\end{array}$ \\
\hline 10 & $50.5 \%$ & $37.9 \%$ & $6.3 \%$ & $2.1 \%$ & $3.2 \%$ \\
\hline 11 & $51.6 \%$ & $35.8 \%$ & $9.5 \%$ & $1.1 \%$ & $2.1 \%$ \\
\hline 13 & $53.1 \%$ & $24.4 \%$ & $7.8 \%$ & $2.6 \%$ & $2.1 \%$ \\
\hline 14 & $2.1 \%$ & $6.3 \%$ & $7.4 \%$ & $47.4 \%$ & $36.8 \%$ \\
\hline 15 & $6.3 \%$ & $15.8 \%$ & $17.9 \%$ & $40 \%$ & $20 \%$ \\
\hline
\end{tabular}

Table III shows that learners are glad to see the impact of FS on their learning. These learners believe that teacher's proper FS can stimulate their responses and create more enjoyable and harmonious context for EFL class. 88.4\% participants (among them 50.5\% strongly) agree that teachers' face-saving acts can efface their dread in English learning. As to Item $11,87.4 \%$ of the participants (51.6\% among them strongly) agree that face concern for learners can increase their confidence in teachers. In Item 13, 87.5\% of the participants state that most learners cannot boldly answer questions and show their opinions in English class because of their fear of making mistakes and losing face in public. Whereas in Item 14 and 15, most of the participants, accounting to 84\% (among them 36.8\% strongly disagree) and $60 \%$ (among them 20\% strongly disagree) respectively disagree with the given statements. Thus overall, these learners have recognized the important role of teachers' facework strategies within their EFL classroom.

Furthermore, in order to investigate more about learners' attitudes toward the application of FS within the EFL classroom, learners are asked to identify three given statements as shown in Table IV.

TABLE IV:

MEAN AGREEMENT WITH OPINION STATEMENT ABOUT LEARNERS' ATTITUDES TOWARD TEACHERS' FS

\begin{tabular}{|l|l|c|}
\hline Item & Attitudes toward Teachers' FS & Mean \\
\hline 7 & $\begin{array}{l}\text { Though many teachers recognized the function of “face" in the classroom interaction, they } \\
\text { cannot employ relevant effective strategies to accelerate the teaching process. }\end{array}$ & 3.71 \\
\hline 8 & In my English study, I prefer amiable teachers who are more considerate of their students. & 4.12 \\
\hline 9 & $\begin{array}{l}\text { Teachers should perceive their students' mentality profoundly so that they can employ } \\
\text { appropriate strategies to help teaching. }\end{array}$ & 3.65 \\
\hline
\end{tabular}

Table IV shows all the learners hold the view that it is necessary for teachers to apply FS according to the specific teaching tasks, teaching contexts and especially learners' face-needs in EFL class. The mean for Item 8 is 4.12 , which is the highest one in Table IV. The next mean comes for Item 7, which is 3.71. The mean for Item 9 is 3.65. The results indicate a fact that there are still many teachers fail to recognize the significance of FS. It also shows that the learners expect their teachers to be more considerate of their face-needs within EFL classrooms.

Table III to Table IV reveals that these English learners believe that FS application is significant for both EFL teaching and learning. It not only can accelerate teaching process and achieve teaching objectives, but also can stimulate learners' self-esteem and enthusiasm in study. So the demand for teachers to employ more effective FS in the classroom becomes clearer.

Altogether, results of the questionnaire survey show that teachers have recognized the importance of non-conflict teaching context to the success of interactive EFL classroom and acknowledged the value of initiating more FS. And it also indicates that learners expect their face-needs in class to be satisfied and demand their teachers to design a more effective teaching with proper FS under appropriate situations.

\section{FACE ISSUES IN CURRENT EFL ClassRoOM}

The questionnaire surveys outline the salient face issues as well as offer a glimpse of teachers' application of facework strategies in EFL classroom. It examines learners' face-needs and teachers' face concerns for their students in class. Then it reflects teachers' motives of applying FS and the problems they meet in designing and employing FS in 
their classroom. It also reveals how teachers set their own roles in FS application and implement various types of FS within real situation.

With the data collected from questionnaires, three points are worthy of discussion: teachers' perceptions of FS application; important factors to be considered in FS application; and teachers' classroom implementations.

\section{A. Teachers' Perceptions of FS Application}

By using data sources, we learned that teachers in this study held four perceptions about FS application. They believe that (a) FS in the classroom should consider students' face-needs and emphasize harmonious interaction, (b) FS application depends on teaching contexts, teaching tasks, and teaching procedures, (c) FS should be used appropriately in EFL classroom, (d) FS are often used sequentially with some face-threatening acts. No matter what kind of FS teachers choose, it is necessary for them to apply FS on the basis of learners' needs and current development in teaching.

The survey shows that teachers recognized the importance of applying more FS to increase learners' self-esteem and interests in their English study. It also shows that teachers believe that FS could gain more positive effects for both learners and themselves in EFL classroom. They suggest that learners can be encouraged to make more progress if the purpose of FS is to stimulate learners' initiative in class. Teachers are clearly aware that different classes do provide different opportunities for the employment of FS. They agree that FS boosts the interactive language teaching, so an appropriate proportion of FS in EFL classroom is important. Although there is potential for harmonious communication in class after FS is put forth, the teachers are unsure of the extent to which they have the time to promote it and whether or not all learners are capable of giving responses as they expected.

\section{B. Important Factors to Be Considered in FS Application}

From the research sources, we come to know that FS should be viewed as a flexible teaching aid that teachers are still developing. Through teachers' practical classroom implementations, we believe that complexity in FS application involves not only the learners' variables, but also contextual elements of teaching such as teaching contexts, teaching tasks, and teaching procedures.

The most important factor might be the learners' variables. The trend from the data sources reveals that teachers' view of FS is focusing on learners. Teachers support the idea that FS can be effective when learners' needs are appropriately satisfied. According to the questionnaires, teachers' choice of FS would be influenced by the face-needs of learners. The second factor might be the specific teaching context. Teachers' practices revealed from the study demonstrate that decisions on adopting FS must be related to certain teaching context, especially in such a Chinese cultural environment. The third factor might be teaching tasks and procedures. Teachers' application of FS in their classroom shows that teachers often compromise their personal beliefs of language teaching with the procedures of particular lessons.

The data sets have uncovered the complexity which teachers constantly face in designing and using FS within EFL classroom. Through the study we know that current perceptions of face management might have influenced teachers' perceptions of FS to a certain degree. In practice, they still resort to their own personal ideas and experiences, thus developing their perceptions.

\section{Teachers' Classroom Implementations}

Teachers in this study have their own perceptions about face-needs and FS. For example, those teachers implement their perceptions of FS in their actual teaching according to particular learners in particular teaching contexts. They maintain such a good rapport with learners that their FS become clearer and better organized.

Teachers are found to use different strategies in implementing different facework in the EFL classrooms. Most of the FS which teachers applied in EFL classrooms support results obtained from the questionnaires, considering students' face-needs and classroom contexts.

We have known that there is no single way and no particular comprehensive set of FS that are decisive for facework application. Each teacher has his or her own profile or agenda which contributes to effective facework applying in class. Indeed, there is a small set of beliefs that seem to be of high importance for effective language teaching. However, beyond this small set, each teacher achieves his or her FS in a different way, by using a different combination of perceptions on FS application.

\section{Pedagogic Considerations}

On the basis of earlier discussion, we now attempt to explore the practical implications of the research, which has a corresponding pedagogic role in EFL teaching.

\section{A. Focusing on Learners' Face-needs}

Current perspectives of language teaching and learning suggest there is a shift from a teacher-centered classroom to a learner-centered classroom which is more communicative and authentic. Thus the need for paying more attention to learners' variables is put forward.

As mentioned in former sections, teachers' FS mainly deal with learners' face-needs which refer to the needs for 
protecting, supporting or enhancing their public image. So, before teachers apply a certain FS, it is better for them to focus on learners' face-needs: the needs for control, the need for approval and the need for admiration (Lim, 1991).

\section{The Need for Control}

Face control is concerned with individual requirements for freedom and personal authority. It is related to people's need for others to acknowledge their individual autonomy and self-sufficiency. As Lim (1991, p.425) suggests, it involves people's "image that they are in control of their own fate, that is, they have the virtues of a full-fledged, mature, and responsible adult." This type of face includes such values as "independent", "in control of self", "initiative", "mature", "composed", "reliable", and "self-sufficient". When learners claim these values for themselves, they want to be self-governed and free from others' interference, control or imposition. The claim for face control, in other words, is embodied in the desire to have freedom of action.

\section{The Need for Approval}

Face approval is concerned with individual requirements for affiliation and social contact. It is related to people's need for others to acknowledge their friendliness and honesty. This type of face includes such values as "likable", "acceptable", "friendly", "agreeable", "cooperative", "alike", and "affiliated". When learners claim these values for themselves, they want to be thought of as a member of an in-group. Since it is concerned with the social aspect of the learner, the loss of which makes it impossible for him/her to function appropriately within a social group. Thus face approval reflects the desire to be treated with respect and dignity.

\section{The Need for Admiration}

Face admiration is concerned with individual need for display of respect from others. It is related to people's need for others to acknowledge their talents and accomplishments. This type of face is similar to what the Chinese call mien-tsu, or prestige acquired through success and social standing. One's mien-tsu is built up through high position, wealth, power, ability, through cleverly establishing social ties to a number of prominent people, as well as through avoidance of acts that would cause unfavorable comment. People growing up in any community have the same claim to mien-tsu, an honest, decent "face"; but their mien-tsu will differ with the status of the family, personal ties, ego's ability to impress people, etc. This type of face-need emphasizes such issues as being "knowledgeable", "intelligent", "wise", "experienced", "influential", "prosperous", "accomplished", "attractive" and "distinguished". Thus when learners claim these values for themselves, they want others to acknowledge their capabilities, success, reputation and accomplishments.

\section{B. Choosing Appropriate Facework Strategies}

Different types of face are supported by different kinds of facework, so teachers should choose appropriate FS according to learners' face wants.

Tact facework is characterized by the effort to maximize the freedom of action of the learners and minimize the impositions that restrict their freedom of action. Thus, tact facework strategies often ask for suggestions and directions, avoid explicit directives, and use pleas and conventional indirectness.

Solidarity facework minimizes the differences and maximizes the commonalities between the teacher and the learners. Thus, strategies of solidarity facework tend to use informal or intimate language, and emphasize the necessity to cooperate, similarities, shared fate, and mutual trust.

Approbation facework is characterized by the effort to minimize blame and maximize praise of the teacher. Strategies of approbation tend to ignore or understate negative aspects of learners and to notice or exaggerate positive aspects of them.

Face-giving, which is "approach-based" (Brown and Levinson, 1987) facework, actively promotes the given face-want of learners, thus being the most supportive facework of the four. Specifically, the face-giving strategy of tact gives autonomy to the learners; the face-giving strategy of solidarity actively involves learners in the group; the strategy of approbation shows admiration for achievement of abilities. The face-giving strategy is normally used when there is no direct threat to the particular type of face. Since the face-giving strategies actively acknowledge the positive attributes of the learners, they are more supportive when they are more directly expressed.

Withdrawal, moderation, and disregard are used when teachers perform certain face-threatening acts. They, in other words, are "avoidance-based" (Brown \& Levinson, 1987) facework, which are used to mitigate the threat to the face of the learners. Withdrawal, gives up performing the intended face-threatening act in order to avoid threatening the learners' face. Disregard, on the other hand, does not pay any attention to their face-want. It is the lowest in the amount of face support. Moderation performs the intended face-threatening act but attempts to mitigate the possible face-threat. Indirectness has been proposed as the most important principle for moderating face-threat.

\section{Ways of Enacting Facework Strategies}

There are different ways of enacting disregard, moderation, and face-giving strategies of tact, solidarity, and approbation.

Moderating tactics of facework tact attempt to express one's wish to avoid imposing upon the other. Thus, the tactics vary in the amount of face-support dependent upon the indirectness of expressing the intended imposition. "Pleading", "advice", "conventional indirectness" and "debt incurrence" are indirect, however, they do not moderate face-threatening greatly. While "unconventional indirectness", which gives hints or association clues, and 
"experimenting", which explores the possibility for the learner to volunteer, are very indirect, thus significantly mitigating the threat to the learner's autonomy face. Autonomy face-giving strategies are not intended to avoid threatening the learner's face, but purported to give leeway to the learner. "Nomination" dedicates, endows, or transfers the leadership to the learner; "volunteering" expands learner's domain of control by offering service; and "submission" gives relative autonomy to the learner by limiting his/her own.

Moderating tactics of solidarity are used when a teacher needs to threaten the learner's fellowship-face, but wants to avoid directly depreciating the learner as a member of in-group. Fellowship-face-giving tactics are used when the teacher wants to actively promote the learner's want to be involved. As mentioned earlier, face-giving tactics are more supportive, when they are more direct. "Similarity", "informality", "agreement" and "pre-supposition" actually imply, but not directly state that the teacher approves of the learner as a member of an in-group. Whereas, "appreciation", which approves of the learner's character, "empathy", which shows compassion, "cooperation", which emphasizes the obligation to cooperation, and "affirmation", which reaffirms the close relationship, express the teacher's intention to include the learner more or less directly.

Moderating tactics of approbation facework express a teacher's intention to avoid disapproving of the learner. The tactics, therefore, are more face-supportive if they are more indirect in expressing the disapproval. "Resentment", which disapproves of the learner's performance, but leaves his/her competence intact; "aspiration", which implies that the performance is not bad; "diminutive", which understates the problem, are still more or less direct in the expression of disapproval. However, "suggestion", which suggests the ways to make the performance perfect, "contradiction", which approves of some related aspects and moderates the problem, and "encouragement", which approves of the potential of the learner, are very indirect in disapproval because they also express certain approval. Competence-face-giving tactics, such as "comparative approval", "positive comments", and "admiration", actually promote the learner's want to be respected by giving approvals.

\section{CONCLUSION}

The study proves that facework is a central and enduring feature of all interpersonal relationships in classroom communication. It is concerned with the communication activities that help to create, maintain, and sustain the connections between teacher and learners.

The sources together with the data collected from this study provide teachers advice about how to conduct a EFL class with proper FS. It is important for teachers to recognize their role on FS application. We hold that no matter what types of facework strategies are applied in EFL classrooms, the purpose is to create a pleasant and harmonious context for the learners, to initiate their self-esteem and enthusiasm in English study, and hence achieve more effective teaching.

The study makes a case for the contributing research into teachers' concerns and practices. It also leads us to a fuller and more realistic understanding of the role of FS in an EFL classroom. The value of this study lies in the fact that it increases teachers' awareness of their own conventional everyday behavior in an EFL classroom. It is of particular significance in providing professional teachers with first-hand data for subsequent teacher development on FS application

\section{REFERENCES}

[1] Brown, P. \& S. C. Levinson. (1978). Universals in Language Usage: Politeness Phenomenon. In: E. Goody (Ed.), Questions and Politeness: Strategies in Social Interaction. Cambridge: Cambridge University Press.

[2] Brown, P. \& S. C. Levinson. (1987). Politeness: Some Universals in Language Use. Cambridge, UK: Cambridge University Press.

[3] Goffman, E. (1967). Interaction Ritual: Essays on Face-to-face Behavior. New York: Doubleday.

[4] Goffman, E. (1972). On Facework: an Analysis of Ritual Elements in Social Interaction. In: J. Laver and S. Hutcheson, (Eds.), Communication in Face-to-face Interaction, 319-346. Harmondsworth: Penguin.

[5] Kim, M. S. (2009). The Relationship between Self -- Construal, Perceived Face Threats, and Facework during the Pursuit of Influence Goals. Journal of International and Intercultural Communication, 2(4) : 318-343.

[6] Lim, T.S., \& J.W. Bowers. (1991). Facework: Solidarity, Approbation, and Tact. Human Communication Research, 17:415-450.

[7] LoCastro V. (2003). An Introduction to Pragmatics: Social action for Language Teachers. Ann Arbor: The University of Michigan Press.

[8] Mao, L. M. (1994). Beyond Politeness Theory: 'Face' Revisited and Renewed. Journal of Pragmatics, 21: 451-486.

[9] Mey, J. (2003). Introduction: 'About Face'. Journal of Pragmatics, 35: 1451.

[10] Penman, R. (1994). Facework in Communication: Conceptual and Moral Challenges. In: S. Ting-Tomey (Ed.), The Challenge of Facework: Cross-Cultural and Interpersonal Issues, 15-45. Albany, NY: State University of New York Press.

[11] Spencer-Oatey, H. (2007). Theories of Identity and the Analysis of Face. Journal of Pragmatics, 39: 639-656.

[12] Ting-Toomey, S. (1994). Face and Facework: An introduction. In: Stella Ting-Toomey (Ed.), The Challenge of Facework, 1-14. Albany, NY: State University of New York Press.

[13] Ting-Toomey S. \& A. Kurogi. (1998). Facework Competence in Intercultural Conflict: An Updated Face-negotiation Theory. International Journal of Intercultural Relations, 22(2):187-225.

[14] Wood, L.A. \& O.K. Rolf. (1994). The Analysis of Facework in Discourse: Review and Proposal. Journal of Language and Social Psychology, 13: 248-277.

[15] Yule, G. (2000). Pragmatics. Shanghai: Shanghai Foreign Language Education Press. 
Qian Huang, Changsha Hunan, Chinam 24/3/1978, master of arts in English Language and Literature, Central South University, Changsha, China, 2003, Applied Linguistics.

She has been working in Zhejiang University of Finance \& Economics since 2004, teaching a range of English courses like College English, English Writing and English Listening, etc. She has published several Chinese articles and is currently interested in English teaching research and comparative literature studies. 